\title{
AVALIAÇÃO DA EFICIÊNCIA DE INCORPORAÇÃO DE DICLOFENACO DE SÓDIO EM PARTÍCULAS DE SERICINA E ALGINATO
}

\author{
J. M. M. VIDART ${ }^{1 *}$, T. A. SOARES ${ }^{1}$, T. L. da $\operatorname{SILVA}^{1}$, M. L. GIMENES ${ }^{2}$, \\ M. G. A. VIEIRA ${ }^{1}$, M. G. C. da SILVA ${ }^{1}$ \\ ${ }^{1}$ Universidade Estadual de Campinas, Faculdade de Engenharia Química \\ ${ }^{2}$ Universidade Estadual de Maringá, Departamento de Engenharia Química \\ e-mail: jacyaramartins@gmail.com
}

\begin{abstract}
RESUMO
O presente estudo visa à avaliação da eficiência de incorporação de diclofenaco de sódio (DS) em partículas de sericina (ser) e alginato (alg) produzidas pelo método de gotejamento seguido de reticulação. A sericina é uma proteína presente nos casulos do bicho-da-seda (Bombyx mori) que apresenta diversas características necessárias para a incorporação de fármacos, sendo que a mistura com o biopolímero alginato pode fornecer características mais adequadas para melhorar a encapsulação. O DS é um antiinflamatório amplamente utilizado e que apresenta efeitos colaterais recorrentes no sistema gastrointestinal, além de necessitar de múltiplas doses diárias para manter o seu efeito terapêutico no plasma sanguíneo. Diante disso, a modificação da forma farmacêutica de apresentação do DS torna-se desejável para minimizar os efeitos colaterais e não adesão do paciente ao tratamento. Formulações com diferentes frações de sericina e alginato em sua composição foram produzidas e avaliadas quanto à eficiência de incorporação de DS, sendo que as partículas F5 (38\% ser $+31 \%$ alg $+31 \%$ DS) e F6 (36\% ser $+36 \%$ alg $+28 \%$ DS $)$ apresentaram-se mais viáveis para a encapsulação, com eficiências de $56,3 \%$ e $47,1 \%$, respectivamente. Sendo assim, análises de MEV para verificar a morfologia das superfícies e FTIR para verificar a interação da blenda com o DS, das formulações F5 e F6 e da formulação F12 (sem presença de sericina) foram realizadas, sendo possível comprovar as melhoras das características de encapsulação do DS na presença da blenda de sericina e alginato.
\end{abstract}

\section{INTRODUÇÃO}

A sericina é uma proteína globular hidrossolúvel, presente nos casulos do bichoda-seda (Bombyx mori) (ARAMWIT, SIRTIENTONG e SRICHNA, 2012), que constitui de 25 a $30 \%$ da massa seca do casulo (ZHANG, 2002). A presença de sericina nos efluentes da indústria da seda impacta negativamente o meio ambiente, sendo assim, há um crescente interesse na recuperação da sericina dos efluentes de seda nos últimos anos (CAPAR, AYGUN e GECIT, 2009).

A proteína sericina apresenta excelentes propriedades antioxidantes e antibacterianas (KONGDEE, BECHTOLD e TEUFEL, 2004), capacidade de gelificação, capacidade de retenção de umidade e propriedades adesivas (PADAMWAR e PAWAR, 2004). Estas características têm atraído a atenção de pesquisadores para diversos usos, sendo exploradas atualmente em aplicações como cosméticos, suportes para enzimas 
imobilizadas, suplementação alimentar, materiais médicos e farmacêuticos, e fibras funcionais (MONDAL, TRIVEDY e KUMAR, 2007). Devido aos grupos funcionais reativos presentes na estrutura química da sericina, uma alternativa para melhorar suas propriedades estruturais é a formação de blendas a partir dessa proteína (MONDAL, TRIVEDY e KUMAR, 2007).

O biopolímero alginato, amplamente empregado nas indústrias farmacêutica $\mathrm{e}$ alimentícia (GARCIA-CRUZ, FOGGETTI e SILVA, 2008), apresenta algumas propriedades que o tornam adequado para a incorporação de fármacos, como a sua bioadesividade, biocompatibilidade, biodegradabilidade e versatilidade química que possibilita modificações adicionais para adequar as suas propriedades (SOSNIK, 2014). Desta forma, a produção da blenda entre sericina e alginato pode fornecer partículas com propriedades favoráveis para a incorporação de fármacos (KHANDAI et al., 2010).

O diclofenaco de sódio (DS) é uma substância anti-inflamatória não esteroidal, utilizado para reduzir a inflamação e aliviar a dor, agindo como analgésico em situações de artrites e lesões agudas (NAYAK e PAL, 2011). A meia-vida biológica desse fármaco é de $1 \mathrm{~h}$ a $2 \mathrm{~h}$, sendo necessárias múltiplas doses diárias para manter o efeito terapêutico (SINHA et al., 2015). Os efeitos colaterais mais comuns desse fármaco são os relacionados com o trato gastrointestinal, incluindo hemorragia, erosão da mucosa e ulceração (NAYAK e PAL, 2011).

$\mathrm{O}$ custo das pesquisas na área farmacêutica para o desenvolvimento de novas substâncias ativas é, em geral, muito elevado, sendo de grande interesse o desenvolvimento de novas formas farmacêuticas com os princípios ativos já existentes (ALLEN, POPOVICH e ANSEL, 2007). Blendas poliméricas adequadas podem melhorar a encapsulação da droga e, além disso, solucionar problemas presentes nos ativos, como a baixa absorção, redução dos efeitos colaterais e não adesão do paciente ao tratamento (SINHA et al., 2015).

O presente estudo tem como objetivo a avaliação da eficiência de incorporação do diclofenaco de sódio em partículas a base de sericina e alginato. A morfologia do material produzido e sua estrutura química foram avaliadas por microscopia eletrônica de varredura e espectroscopia na região do infravermelho com transformada de Fourier, respectivamente.

\section{MATERIAL E MÉTODOS}

\subsection{Extração da Sericina}

Os casulos do bicho-da-seda Bombyx mori, utilizados nos experimentos, foram obtidos na empresa de fiação de seda BRATAC, com sede na cidade de Londrina, Paraná. A preparação dos casulos para a extração de sericina consistiu na limpeza manual dos mesmos, redução de tamanho, lavagem com água corrente, enxague com água deionizada e secagem em estufa a $50{ }^{\circ} \mathrm{C}$ por $12 \mathrm{~h}$. Após esse período, os casulos foram colocados em erlenmeyer com água deionizada na razão de $40 \mathrm{~g}$ de casulo para $1 \mathrm{~L}$ de água, e em seguida, conduzidos à autoclave para o processo de extração da sericina por 40 min a pressão manométrica de $1 \mathrm{kgf} / \mathrm{cm}^{2}$ e temperatura de $120^{\circ} \mathrm{C}$.

A fim de realizar o fracionamento da sericina, foi utilizado o método de precipitação por congelamento. Nessa etapa, a solução de sericina extraída foi acondicionada em ambiente fechado e mantida em temperatura ambiente por $12 \mathrm{~h}$ e, logo em seguida, em congelador comum por um período de $24 \mathrm{~h}$. Após esse período, a solução foi descongelada e filtrada com papel filtro de porosidade $14 \mu \mathrm{m}$. A concentração da solução obtida foi ajustada para $25 \mathrm{~g} / \mathrm{L}$. 


\subsection{Preparação da Blenda e Incorporação do Fármaco}

A metodologia empregada para produzir a blenda de sericina e alginato foi adaptada de Silva et al. (2013) e Khandai et al. (2010). Para tanto, a solução de sericina $2,5 \%$ $(\mathrm{m} / \mathrm{v})$ foi aquecida em autoclave a $70{ }^{\circ} \mathrm{C}$ por 10 min e então, foi agitada mecanicamente a $4000 \mathrm{rpm}$ em Ultraturrax ${ }^{\circledR}$ até que atingisse $55^{\circ} \mathrm{C}$. Em seguida, alginato de sódio (Sigma-Aldrich) foi adicionado à solução de sericina mantendo-se a agitação até a completa homogeneização da blenda.

Com a blenda formada, procedeu-se à incorporação de diclofenaco de sódio. Foram adicionados $2 \mathrm{~g}$ do fármaco à formulação sob agitação de $8000 \mathrm{rpm}$ em Ultraturrax $^{\circledR}$ até completa homogeneização. As diferentes formulações preparadas são apresentadas na Tabela 1.

Tabela 1 - Formulações das partículas de sericina e alginato com diclofenaco de sódio incorporado.

\begin{tabular}{c|c|c|c}
\hline Formulação & $\begin{array}{c}\text { Sericina } \\
(\mathrm{g})\end{array}$ & $\begin{array}{c}\text { Alginato } \\
(\mathrm{g})\end{array}$ & $\begin{array}{c}\text { Diclofenaco } \\
\text { de sódio }(\mathrm{g})\end{array}$ \\
\hline F1 & 2,5 & 0,50 & 2,0 \\
\hline F2 & 2,5 & 1,00 & 2,0 \\
\hline F3 & 2,5 & 1,25 & 2,0 \\
\hline F4 & 2,5 & 1,50 & 2,0 \\
\hline F5 & 2,5 & 2,00 & 2,0 \\
\hline F6 & 2,5 & 2,50 & 2,0 \\
\hline F7 & 2,5 & 2,60 & 2,0 \\
\hline F8 & 2,5 & 2,80 & 2,0 \\
\hline F9 & 2,5 & 3,00 & 2,0 \\
\hline F10 & 2,5 & 3,30 & 2,0 \\
\hline F11 & 2,5 & 3,60 & 2,0 \\
\hline F12 & - & 4,00 & 2,0 \\
\hline
\end{tabular}

\subsection{Preparação das Partículas}

As partículas foram preparadas pelo método de gotejamento seguido de reticulação, conforme empregado por Silva et al. (2013). Nesse método, a blenda de sericina e alginato contendo o fármaco incorporado foi gotejada, com o auxílio de uma bomba peristáltica, em uma solução de cloreto de cálcio $3 \%(\mathrm{~m} / \mathrm{v})$ sob agitação magnética, de maneira a ocorrer uma rápida gelificação da formulação. Em seguida, as partículas foram mantidas sob agitação em Jar Test a 100 rpm, durante $30 \mathrm{~min}$. Por fim, as partículas foram lavadas com água deionizada e secas à temperatura ambiente.

\subsection{Eficiência de Incorporação}

Com a finalidade de determinar a eficiência de incorporação do diclofenaco de sódio à blenda, $0,01 \mathrm{~g}$ de micropartículas moídas em almofariz de porcelana foram transferidas para um balão volumétrico de $25 \mathrm{~mL}$, onde se adicionou $15 \mathrm{~mL}$ de metanol. Em seguida, o balão foi colocado em banho ultrassônico modelo Brason 1510-USA por 30 min, para a dissolução da amostra. Após esse período, completou-se o volume do balão volumétrico com metanol, deixando-o em repouso por $1 \mathrm{~h}$, para a total sedimentação de toda a suspensão. Por fim, coletou-se uma alíquota de $400 \mu \mathrm{L}$, a qual foi diluída com metanol em balão volumétrico de $10 \mathrm{~mL}$, a fim de determinar a concentração de diclofenaco de sódio presente na solução.

Para a determinação da concentração de diclofenaco de sódio na solução, utilizou-se um espectrofotômetro modelo UV mini 1240 Shimadzu - Japão, no comprimento de onda de máxima absorção do diclofenaco de sódio, determinado previamente, equivalente a $282 \mathrm{~nm}$. A partir dessas concentrações, foi possível calcular a eficiência de incorporação do diclofenaco de sódio à blenda pela Equação 1.

\%incorp $=\frac{[\text { fármaco obtido }]}{[\text { fármaco teórico }]} \times 100$

Sendo:

\%incorp a eficiência de incorporação, [fármaco obtido] a concentração de fármaco obtida através da leitura espectrofotométrica, e [fármaco teórico] a concentração teórica do fármaco. 


\subsection{Avaliação da interação do fármaco com a blenda polimérica}

A fim de avaliar a interação do fármaco com a blenda polimérica, a análise de espectroscopia de infravermelho com transformada de Fourier (FTIR) foi realizada em espectrômetro (Thermo Scientific, Madison, USA). As medidas foram realizadas no modo de transmitância, utilizando $\mathrm{o}$ acessório snap-in baseplate (método $\mathrm{KBr}$ ), na faixa de $4000-400 \mathrm{~cm}^{-1}$, com resolução de 4 $\mathrm{cm}^{-1}$ e 32 scans.

\subsection{Análise morfológica das partículas}

A morfologia superficial das formulações produzidas foi analisada por microscopia eletrônica de varredura (MEV) (LEO Electron Microscopy, Oxford).

\section{RESULTADOS}

A Figura 1 apresenta as diferentes formulações preparadas, conforme Tabela 1.

Figura 1 - Fotografias das partículas F1 a F12
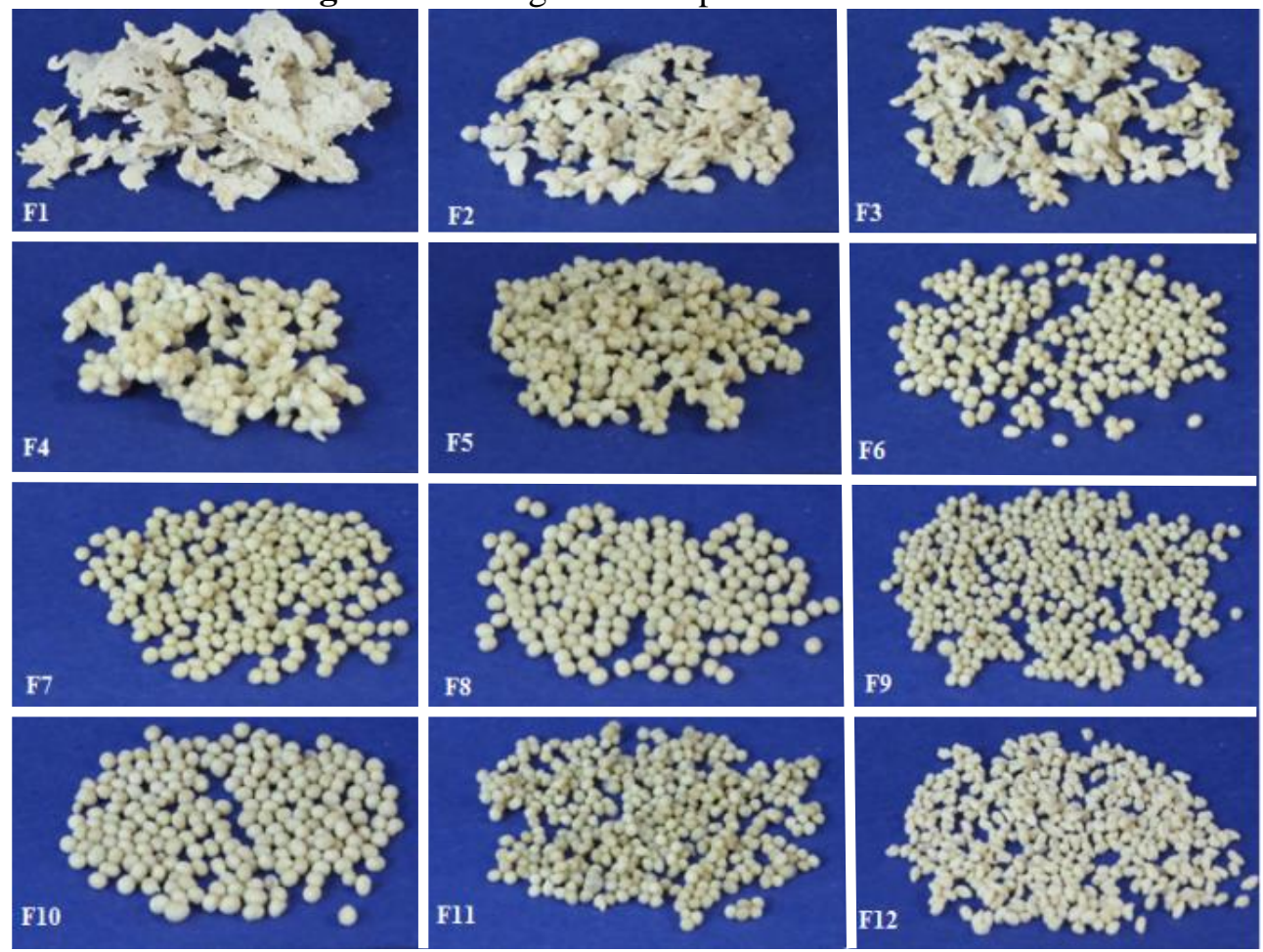

É possível notar que as partículas com baixa fração de alginato em sua composição (F1 a F4) não apresentam uma forma regular, além de se apresentarem mais frágeis. Conforme a fração de alginato na composição da blenda aumenta (F5 a F11), as partículas apresentam forma esférica bem definida e maior rigidez. Já a partícula $\mathrm{F} 12$, a qual não possui sericina em sua composição, apresenta-se sob a forma oval irregular. Diante disso, é possível verificar que as formulações F5 a F11 são mais viáveis para o encapsulamento de diclofenaco de sódio, visto que $\mathrm{F} 1$ a $\mathrm{F} 4$ são muito frágeis $\mathrm{e}$ irregulares, não sendo reprodutíveis. Observase também que a sericina contribui para a formação da partícula com forma bem definida, o que pode melhorar a encapsulação do fármaco.

A Figura 2 mostra a eficiência da incorporação de DS à blenda de sericina e alginato. Embora a formulação F1 apresente a 
maior eficiência de incorporação $(63,6 \%)$, o seu emprego não é indicado por se tratar de uma partícula frágil e sem forma definida. Sendo assim, dentre as formulações viáveis para o encapsulamento de DS, F5 e F6 apresentaram maiores eficiências de incorporação, equivalente a $56,3 \%$ e $47,1 \%$, respectivamente. A baixa eficiência de incorporação apresentada em F12 (34,6 \%) quando comparada às eficiências apresentadas por F5 e F6, confirma a melhora nas propriedades de encapsulação da droga quando empregada a sericina na formulação. Verifica-se ainda que F11 apresenta a menor eficiência de incorporação $(32,3 \%)$ devido à maior fração de alginato presente na blenda, evidenciando que uma fração mássica equilibrada de sericina e alginato favorece a encapsulação.

Figura 2 - Eficiência da incorporação de DS nas partículas F1 a F12.

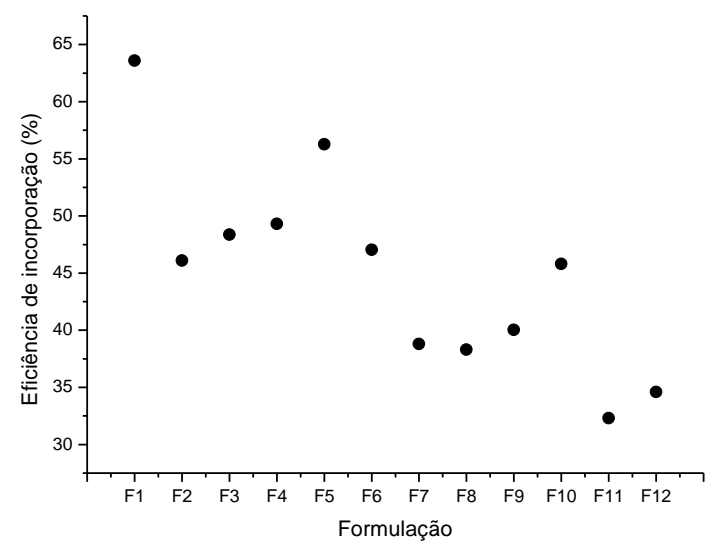

As imagens obtidas por microscopia eletrônica de varredura do DS puro e das formulações F5, F6 e F12 são apresentadas na Figura 3. A partícula F5 com ampliação de 150 x apresenta-se sob a forma esférica regular rugosa, sendo possível observar com uma ampliação de $3000 \mathrm{x}$ a presença de cristais de DS, confirmando a incorporação de DS à blenda de sericina e alginato. Assim como em F5, a partícula F6 apresenta forma esférica bem definida, superfície rugosa e presença de cristais de DS que podem ser observados na sua forma pura em (DS a) e (DS b). Em (12 a) verifica-se a forma oval da partícula F12, além da rugosidade da superfície, enquanto que em (12 b) não foram observados tantos cristais de DS quanto em F5 e F6. Tal fato pode ser justificado pela menor incorporação de DS ao alginato puro, confirmando a melhora das propriedades de encapsulação quando adicionada sericina na formulação.

A Figura 4 apresenta os espectros FTIR do DS, da blenda de sericina e alginato sem a presença de fármaco (blenda) e das partículas F12, F6 e F5. Conforme destacado na figura, verifica-se a presença de bandas características do DS nas formulações. Há evidências de incorporação do DS ao verificar a presença do pico $1530 \mathrm{~cm}^{-1}$, correspondente ao grupo $\mathrm{NH}$, em todas as formulações analisadas e no próprio DS puro. Em $1510 \mathrm{~cm}^{-1}$ e $1580 \mathrm{~cm}^{-1}$ tem-se os picos correspondentes ao estiramento $\mathrm{C}=\mathrm{C}$ e $\mathrm{C}=\mathrm{O}$ do grupo carboxílico, respectivamente. Ainda, é possível evidenciar a incorporação pela presença do pico $723 \mathrm{~cm}^{-1}$ correspondente ao grupo alquila do DS e pelo pico $746 \mathrm{~cm}^{-1}$ correspondente a ligação $\mathrm{C}-\mathrm{H}$ proveniente do anel aromático da molécula de DS. 
Figura 3 - MEV do DS puro, F5, F6 e F12 com (a) ampliação de 150 x e (b) ampliação de 3000 x
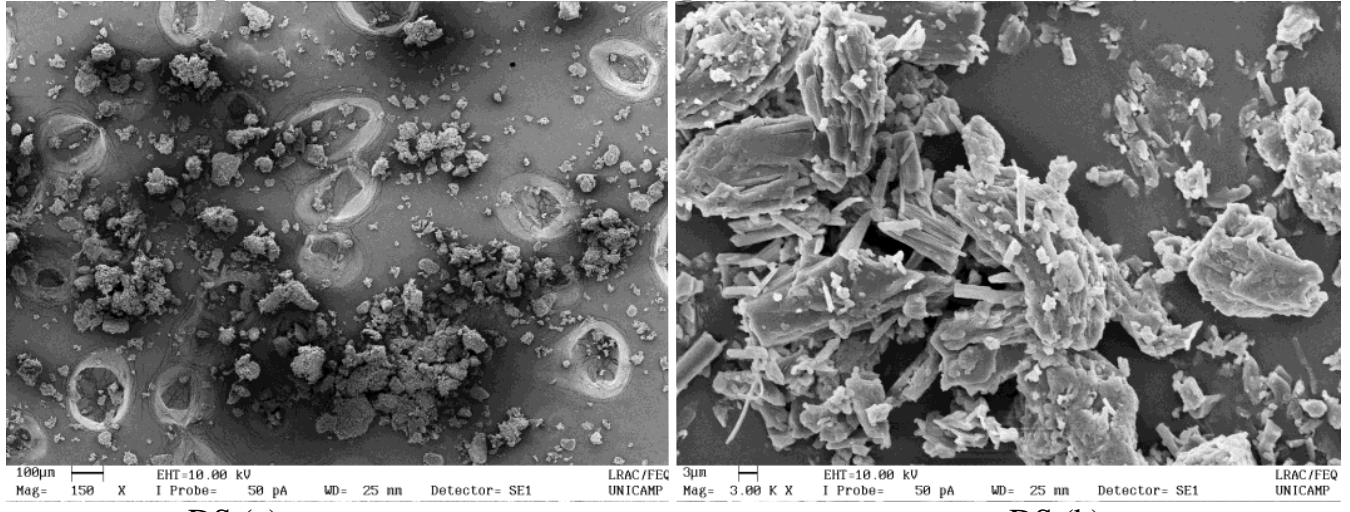

DS (a)

DS (b)
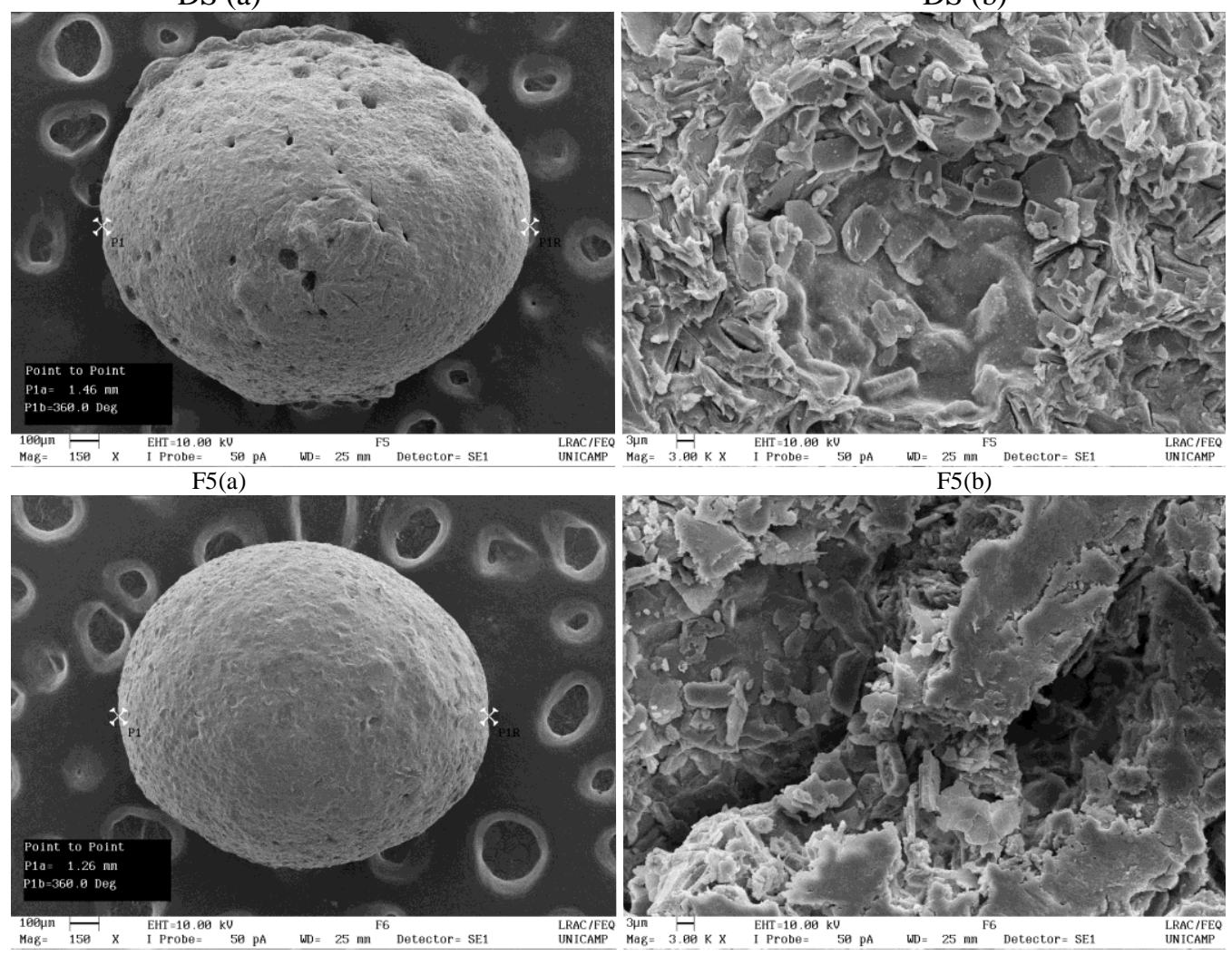

F6 (a)

F6 (b)

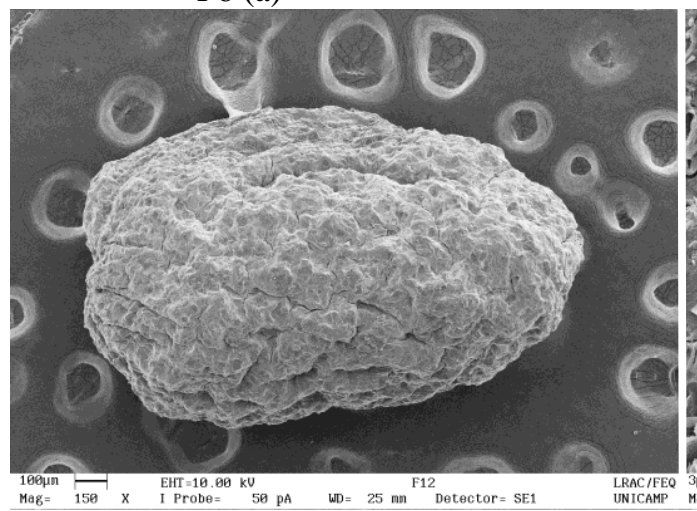

F12 (a)

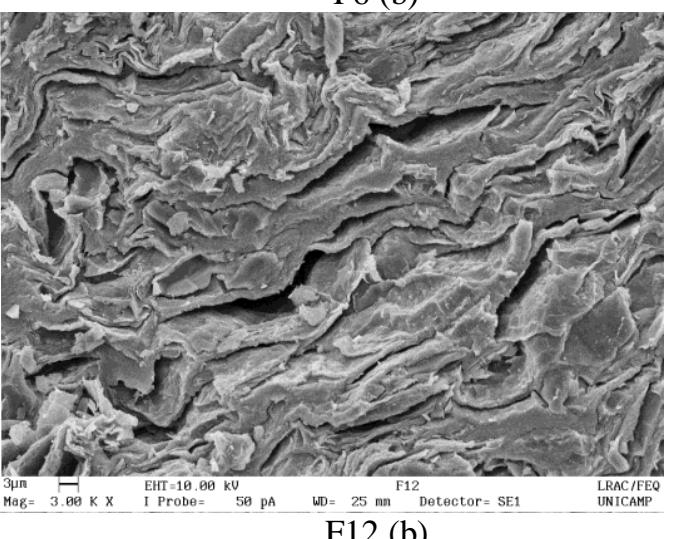


Figura 4 - Espectro FTIR do diclofenaco de sódio (DS), da blenda de sericina e alginato (blenda), da formulação 12 (F12), da formulação 6 (F6) e da formulação 5 (F5).

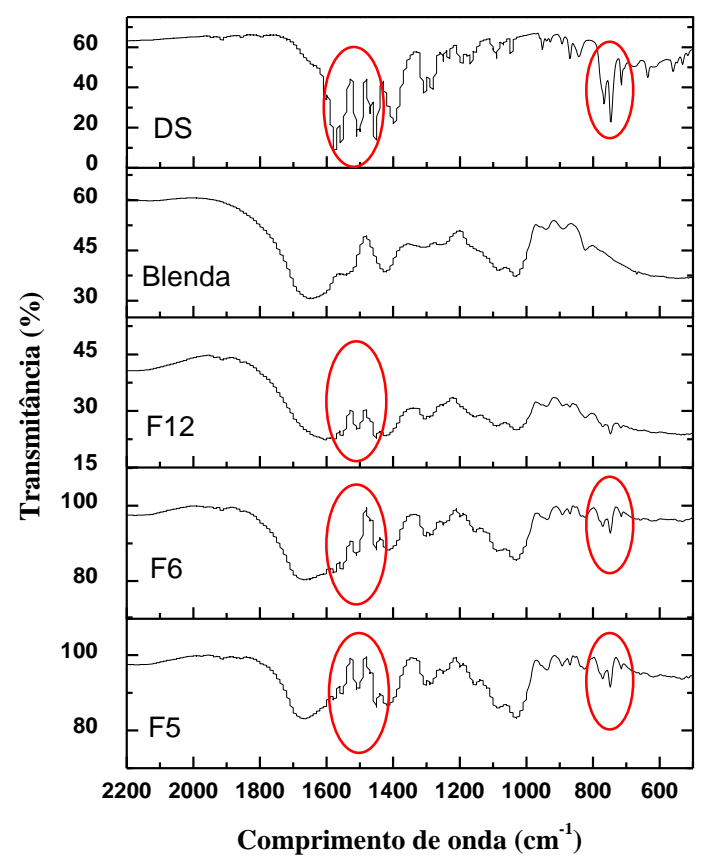

\section{CONCLUSÕES}

Pode-se concluir que a incorporação de diclofenaco de sódio à blenda de sericina e alginato foi satisfatória. Além disso, verificou-se uma grande melhora nas características morfológicas e de encapsulação das partículas contendo sericina e alginato quando comparadas à partícula composta somente por alginato e DS.

As partículas com baixa fração mássica de alginato formam-se sem uma geometria definida e com grande fragilidade, sendo inviáveis para a encapsulação de fármacos. Por outro lado, partículas com maior fração mássica de alginato não apresentaram elevada eficiência de incorporação. Sendo assim, verificou-se que as partículas a base de sericina e alginato ideais para a incorporação de diclofenaco de sódio são aquelas que apresentam frações mássicas de sericina e alginato equilibradas, assim como F5 e F6.

\section{NOMENCLATURA}

DS - Diclofenaco de sódio

MEV - Microscopia eletrônica de varredura FTIR - Espectroscopia Infravermelho com Transformada de Fourier

\section{REFERÊNCIAS}

ALLEN Jr, L. V.; POPOVICH, N. C.; ANSEL, H. C. Formas farmacêuticas e sistemas de liberação de fármacos. $8^{\mathrm{a}} \mathrm{ed}$, Porto Alegre: Ed. Artmed, 2007.

ARAMWIT, P.; SIRTIENTONG, T.; SRICHNA, T. Potencial applications of silk sericin a natural protein from textile industry by-products. Waste management and Research, v.30, n.3, p.217-224, 2012.

CAPAR, G.; AYGUN, S. S.; GECIT, M. R. Separation of sericin from fatty acids towards its recovery from silk degumming wastewaters. Journal of Membrane Science, v.342, p.179-189, 2009.

GARCIA-CRUZ, C. H.; FOGGETTI, U.; SILVA, A. N. Alginato Bacteriano: Aspectos Tecnológicos, Características e Produção. Química Nova, v.31, p.1800-1806, 2008.

KHANDAI, M.; CHAKRABORTY, S.; SHARMA, A.; PATTNAIK, S.; PATRA, C. N.; DINDA, S. C.; SEM, K. K. Preparation and evaluation of algino-sericin mucoadhesive microspheres: An approach for sustained drug delivery. Journal of Advanced Pharmaceutical Research, v.1, p.48-60, 2010.

KONGDEE, A., BECHTOLD, T., TEUFEL, L. Modification of cellulose fiber with silk sericin. Journal of Applied Polymer Science, v.96, p.1421-1428, 2004. 
MONDAL, M.; TRIVEDY, K.; KUMAR, N. The silk proteins, sericin and fibroin in silkworm, Bombyx mori Linn. - A review. Caspian Journal of Environmental Sciences, v.5, n.2, p.63-76, 2007.

NAYAK, A. K.; PAL, D. Development of $\mathrm{pH}$-sensitive tamarind seed polysaccharidealginate composite beads for controlled diclofenac sodium delivery using response surface methodology. International Journal of Biological Macromolecules, v.49, p.784793, 2011.

PADAMWAR, M. N., PAWAR, A. P. Silk sericin and its application: A review. Journal of Scientific and Industrial Research, v.63, p.323-329, 2004.

SILVA, T. L.; GIMENES, M. L.; VIEIRA, M. G. A.; SILVA, M. G. C. Extração de Sericina de Casulos do Bicho da Seda (Bombyx mori) e Formação de Partículas a Base de Sericina e Alginato. Anais do XXXVI Congresso Brasileiro de Sistemas Particulados. Maceió, 2013.

SINHA, P.; UBAIDULLA, U.; HASNAIN, M. S.; NAYAK, A. K.; RAMA, B. Alginateokra gum blend beads of diclofenac sodium from aqueous template using $\mathrm{ZnSO}_{4}$ as a cross-linker. International Journal of Biological Macromolecules, v.79, p.555-563, 2015.

SOSNIK, A. Alginate Particles as Platform for Drug Delivery by the Oral Route: Stateof-the-Art. ISRN Pharmaceutics, p.1-17, 2014.

ZHANG, Y. Q. Applications of natural silk protein sericin in biomaterials. Biothchnology Advances, v.20, p.91-100, 2002.

\section{AGRADECIMENTOS}

Os autores agradecem ao $\mathrm{CNPq}$ e à FAPESP pelo apoio financeiro, e à empresa BRATAC pelo fornecimento dos casulos. 